06

\title{
Рентгеновская фотоэлектронная спектроскопия наноалмазов, полученных измельчением и детонационным синтезом
}

\author{
(С) П.П. Шарин, ${ }^{1}$ А.В. Сивцева, ${ }^{1}$ В.И. Попов ${ }^{2}$ \\ ${ }^{1}$ Институт физико-технических проблем Севера им. Ларионова при ФИЦ ЯНЦ СО РАН, \\ 677980 Якутск, Россия \\ ${ }^{2}$ Северо-восточный федеральный университет им. М.К. Аммосова, \\ 677980 Якутск, Россия \\ e-mail: psharin1960@mail.ru
}

Поступило в Редакцию 15 июня 2020 г.

В окончательной редакции 18 августа 2020 г.

Принято к публикации 24 августа 2020 г.

\begin{abstract}
Методом рентгеновской фотоэлектронной спектроскопии исследованы исходный состав и химическое состояние первичных частиц нанопорошков, полученных измельчением природного алмаза и детонационного синтеза. Показано, что первичные частицы обоих нанопорошков содержат в основном атомы углерода и кислорода. Сигналы в фотоэлектронном спектре от атомов азота, серы, хлора и металлов не превышают уровень шумов. Установлено, что в первичных частицах нанопорошка детонационного синтеза и нанопорошка, полученного измельчением природного алмаза, доли атомов углерода в состоянии $s p^{3}$-гибридизации составляют $\sim 46.5$ и $\sim 67.8 \%$, s $p^{2}$-гибридизации $-\sim 26.8$ и $\sim 17.4 \%$ и в составе кислородсодержащих функциональных групп - 26.7 и $\sim 14.7 \%$ соответственно.
\end{abstract}

Ключевые слова: измельчение природного алмаза, метод РФЭС, элементный состав и химическое состояние поверхности наноалмазов, функциональные группы наноалмазов.

DOI: 10.21883/JTF.2021.02.50364.203-20

\section{Введение}

В работах [1,2] путем мокрого механического измельчения получен нанодисперсный порошок природного алмаза (ПНА), изучены и проанализированы особенности морфологических характеристик и структурного состояния его первичных частиц. Методами просвечивающей и растровой электронной микроскопии, рентгеноструктурного фазового анализа, малоуглового рентгеновского рассеяния и рамановской спектроскопии установлено, что в отличие от нанопорошка детонационного синтеза (ДНА), состоящего в основном из близких по своим размерам частиц сферических форм, нанопорошок ПНА состоит из частиц, имеющих преимушественно пластинчатую форму и более широкий разброс по размерам. Атомная структура же первичных частиц, полученных измельчением природных алмазов, аналогична строению частиц ДНА, т.е. каждая частица нанопорошка ПНА так же, как и частицы ДНА, состоит из монокристаллического алмазного ядра, окруженного оболочкой со сложной структурой, содержащей в основном неалмазные формы углерода с $s p^{2}$-гибридизацией и примеси.

Согласно общепринятой модели, первичные частицы нанопорошков алмаза представляют собой надмолекулы, в которых монокристаллическое алмазное ядро, наряду с атомами углерода в состоянии $s p^{2}$-гибридизации, окружено химически связанными с ними функциональными группами, являющимися их неотъемлемой частью [3-6]. Установлено, что химический состав и содержание функциональных групп зависят от метода и условий синтеза наноалмазов, а также способов их очистки от неалмазных примесей [3-6]. В связи с этим представляет интерес изучение состава и химического состояния первичных частиц нанопорошка, полученного измельчением природного алмазного сырья.

Цель настоящей работы - изучение и сравнительный анализ состава и химического состояния исходных (немодифицированных) частиц нанопорошков, полученных измельчением природных алмазов и детонационным синтезом, методом рентгеновской фотоэлектронной спектроскопии (РФЭС).

\section{1. Метод и объекты исследований}

Метод РФЭС, наряду с рентгеноструктурным фазовым анализом и рамановской спектроскопией, является наиболее информативным методом для изучения химического и фазового составов нанообъектов, сочетающим высокую чувствительность с пространственным разрешением. Сдвиги и форма линий в фотоэлектронных спектрах, обусловленные валентностью и химической связью атомов, обеспечивают использование РФЭС не только для определения элементного состава, но, главным образом, для изучения химических связей наноструктурных материалов [5-7]. В наших экспериментах измерения проводились на фотоэлектронном спектрометре SPECS (Германия) с использованием полусферического анализатора PHOIBOS-150-MCD-9 и рентге- 


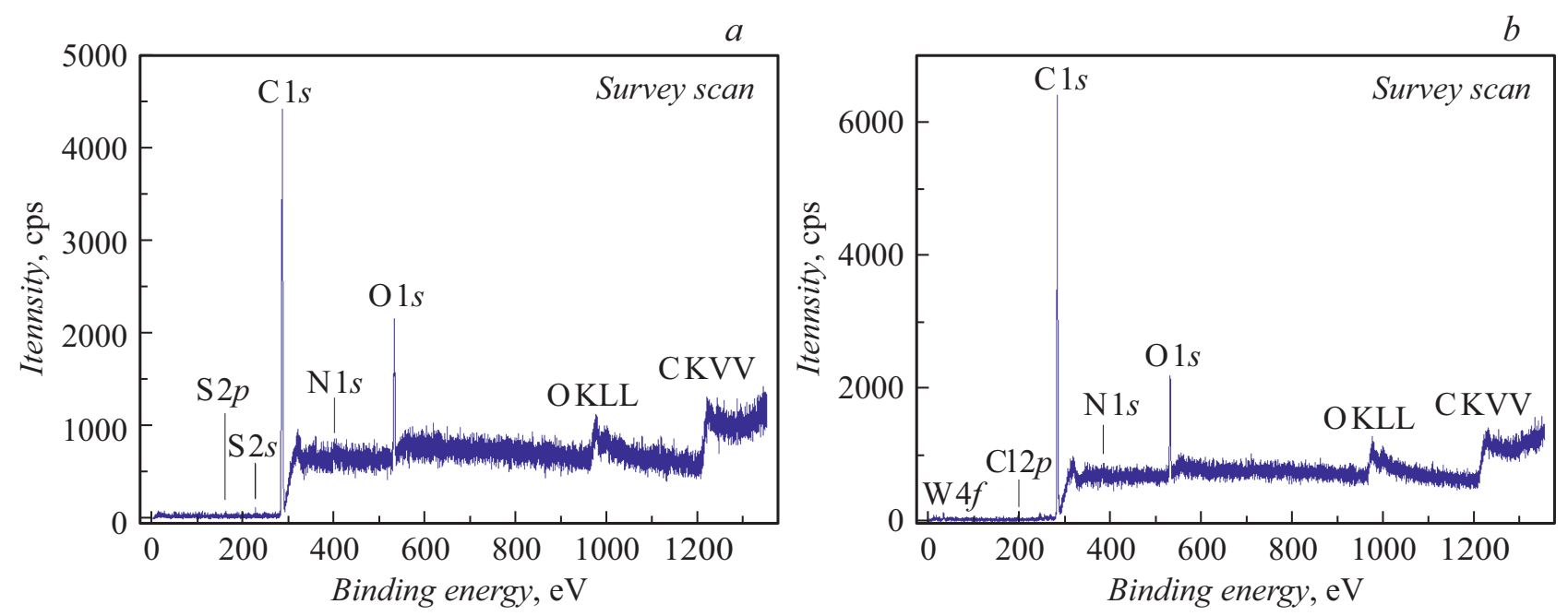

Рис. 1. Обзорные рентгеновские фотоэлектронные спектры образцов частиц нанопорошков ДНА $(a)$ и ПНА $(b)$.

новского монохроматора FOCUS-500 (излучение $\mathrm{Al} K_{\alpha}$, $h v=1486.74 \mathrm{eV}, 200 \mathrm{~W})$. Шкала энергий связи $\left(E_{\text {bind }}\right)$ была предварительно откалибрована по положению пиков остовных уровней $\mathrm{Au} 4 f_{7 / 2}(84.00 \mathrm{eV})$ и $\mathrm{Cu} 2 p_{3 / 2}$ $(932.67 \mathrm{eV})$.

Исследовались несколько образцов из одной партии нанопорошков природного алмаза со средними размерами первичных частиц и удельной поверхностью равными соответственно $\sim 24.0 \mathrm{~nm}$ и $\sim 33.4 \mathrm{~m}^{2} /$ g. Нанопорошок ПНА был получен мокрым измельчением при помощи вибрационной мельницы, в которой мелющими элементами служили стальные шарики $[1,2]$. В качестве исходного сырья использовалась фракция $(-40 \mu \mathrm{m})$ микропорошка природного алмаза. Для очистки нанопорошка ПНА от металлических и других неалмазных примесей, образующихся в процессе мокрого измельчения алмазного сырья, проводили его последовательную обработку в кипящих растворах кислот $\mathrm{HNO}_{3}$ с $\mathrm{H}_{2} \mathrm{SO}_{4}$ и $\mathrm{HNO}_{3}$ c $\mathrm{HCl}$ при температуре $150^{\circ} \mathrm{C}$ в течение $2.5 \mathrm{~h}$ в каждой смеси. Затем нанопорошок ПНА обрабатывали $1 \%$-ным водным раствором едкого натрия при температуре $23^{\circ} \mathrm{C}$ в течение $1.5 \mathrm{~h}$ с последующей многократной промывкой дистиллированной водой.

Для сравнения химического состава и состояния первичных частиц ПНА также исследовались образцы нанопорошка ДНА марки УДА-С-ГО (производство ФНПЦ „Алтай“, г.Бийск) со средним размером первичных частиц $\sim 5.6 \mathrm{~nm}$ и удельной поверхностью $\sim 338.6 \mathrm{~m}^{2} / \mathrm{g}$. Согласно информации, полученной от производителя, данная марка нанопорошка после химической очистки от неалмазных примесей была подвергнута глубокой доочистке с использованием ионообменных и мембранных технологий [8]. Для проведения измерений образцы исследуемых нанопорошков ПНА и ДНА наносились на двусторонний медный проводящий скотч 3М (США).

\section{2. Результаты и их обсуждение}

На рис. 1 приведены обзорные фотоэлектронные спектры образцов нанопорошков ДНА (рис. $1, a$ ) и ПНА (рис. $1, b)$, позволяющие получить общую картину химического состава наноалмазов и наличия остаточных примесей или загрязнений. Обзорные спектры записывались при энергии пропускания анализатора $50 \mathrm{eV}$, отдельные спектральные районы $-20 \mathrm{eV}$. Как видно из рис. 1, в спектрах обоих нанопорошков ДНА и ПНА четко проявляются интенсивные линии, характерные для углерода $(\mathrm{C} 1 s$ и $\mathrm{C} \mathrm{KVV})$ и кислорода (O1s и O KLL). Кроме указанных линий, в образце нанопорошка ДНА наблюдаются слабые, практически на уровне шумов, пики азота $(\mathrm{N} 1 s)$ и серы $(\mathrm{S} 2 s$ и $\mathrm{S} 2 p)$. Согласно литературным источникам (см., например, [3,9]), частицы ДНА, помимо атомов углерода и кислорода, обычно содержат также заметные количества азота (от 2 до 8\%). Низкое содержание азота в наших образцах ДНА - на уровне фонового содержания - может быть объяснено тем, что нанопорошок ДНА марки УДА-С-ГО после химической очистки был подвергнут глубокой доочистке с использованием ионообменных и мембранных технологий, в результате которой, видимо, атомы азота, входящие в состав сорбированных молекул и функциональных групп, практически удалены с наночастиц. В образце частиц нанопорошка ПНА дополнительно зарегистрированы слабые линии от металлических примесей: вольфрама $(\mathrm{W} 4 f)$ и хлора $(\mathrm{Cl} 2 p)$. Других химических элементов, которые могут присутствовать в виде примесей, в частицах нанопорошков в пределах чувствительности метода РФЭС не обнаружено.

В табл. 1 приведены результаты измерений относительного содержания основных элементов - атомов углерода и кислорода, а также отношение их атомных концентраций в образцах нанопорошков ДНА и ПНА. Относительное содержание элементов на поверхности 

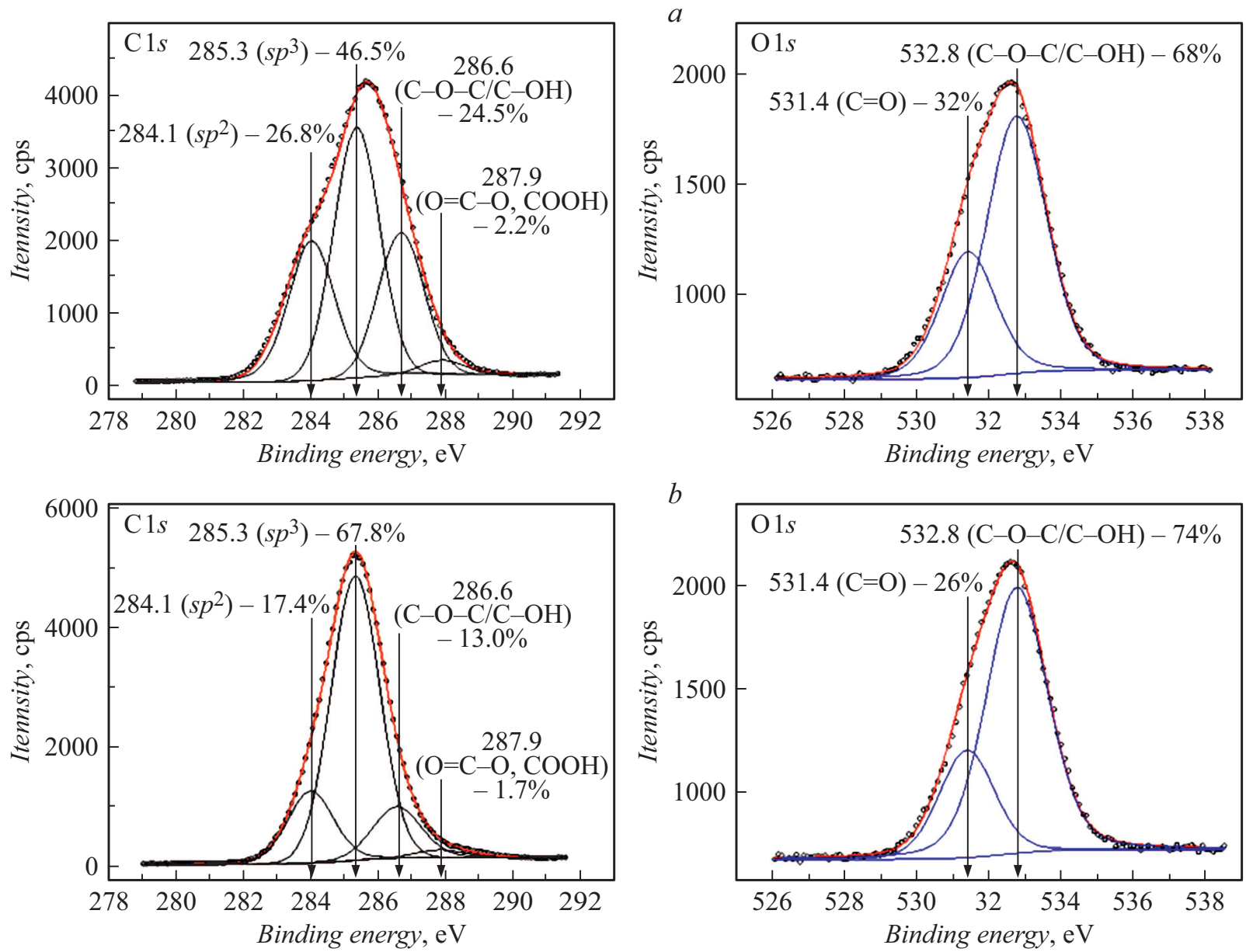

Рис. 2. Остовные линии углерода $\mathrm{C} 1 s$ и кислорода $\mathrm{O} 1 s$ в фотоэлектронном спектре для образцов нанопорошка ДНА (a) и ПНА $(b)$.

Таблица 1. Относительное содержание углерода и кислорода в образцах частиц ДНА и ПНА и их атомные отношения

\begin{tabular}{c|c|c|c}
\hline Образец нанопорошка & $\mathrm{C}$ & $\mathrm{O}$ & $\mathrm{O} / \mathrm{C}$ \\
\hline ДНА & 90.6 & 9.4 & $\sim 0.10$ \\
\hline ПНА & 90.8 & 9.2 & $\sim 0.10$
\end{tabular}

образцов нанопорошков и их атомные отношения определялись по интегральным интенсивностям фотоэлектронных линий, откорректированных на соответствующие коэффициенты атомной чувствительности [10]. Как следует из табл. 1, отношение количества атомов кислорода к количеству атомов углерода для частиц нанопорошков ПНА и ДНА приблизительно одинаковое.

Для детального анализа остовные линии углерода $\mathrm{C} 1 s$ и кислорода $\mathrm{O} 1 s$ были разложены на отдельные спектральные компоненты с помощью свободно распространяемой программы XPSPeak 4.1 [10]. На рис. 2 приведены линии $\mathrm{C} 1 s$ и $\mathrm{O} 1 s$ в фотоэлектронном спектре для образцов нанопорошка ДНА (рис. 2,a) и ПНА (рис. 2,b). Как видно из рис. 2, контур линии углерода $\mathrm{C} 1 s$ образца ДНА имеет слегка асимметричную форму с шириной на полувысоте $(\mathrm{FWHM}) \sim 3.07 \mathrm{eV}$ и относительно меньшую интенсивность по сравнению с формой контура и интенсивностью линии образца ПНА, имеющей ширину на полувысоте $(\mathrm{FWHM}) \sim 2.07 \mathrm{eV}$. Из анализа значений энергии связи отдельных компонент в спектрах линий $\mathrm{C} 1 s$ обоих образцов ДНА и ПНА можно заключить, что наиболее интенсивные пики со значениями энергии связи $285.3 \pm 0.2 \mathrm{eV}$ соответствуют $s p^{3}$-гибридизированному углероду, образующему алмазную кристаллическую решетку [6,9,11-13]. Значения энергий связи пиков, равные $284.1 \pm 0.1 \mathrm{eV}$, характерны для атомов углерода в состоянии $s p^{2}$-гибридизации (как в графите или фуллеренах) [6,9,11-13]. Пики с энергиями связи $286.6 \mathrm{eV}$ соответствуют атомам углерода в составе гидроксильных и эфирных групп (C-OH, C-O-C) [11-13]. Наименее интенсивные пики с энергиями связи $287.9 \pm 0.3 \mathrm{eV}$ характеризуют состояние атомов углерода в составе карбоксильных групп $(\mathrm{O}=\mathrm{C}-\mathrm{O}, \mathrm{COOH})$. Из представленных данных можно определить вклад каждого состояния атомов углерода в общий спектр линии $\mathrm{C} 1 s$ и соотношение $s p^{2} / s p^{3}$ для 
Таблица 2. Вклад состояний углерода в суммарный спектр C1s (\%) в образцах нанопорошков ДНА и ПНА

\begin{tabular}{c|c|c|c|c|c}
\hline $\begin{array}{c}\text { Образец } \\
\text { нанопорошка }\end{array}$ & $\begin{array}{c}s p^{2}, \\
\%\end{array}$ & $\begin{array}{c}s p^{3}, \\
\%\end{array}$ & $\begin{array}{c}\mathrm{C}-\mathrm{O}-\mathrm{C} / \mathrm{C}-\mathrm{OH}, \\
\%\end{array}$ & $\begin{array}{c}\mathrm{COOH}-, \\
\%\end{array}$ & $s p^{2} / s p^{3}$ \\
\hline ДНА & 26.8 & 46.5 & 24.5 & 2.2 & $\sim 0.58$ \\
\hline ПНА & 17.4 & 67.8 & 13.0 & 1.7 & $\sim 0.26$
\end{tabular}

измеренных образцов нанопорошков ДНА и ПНА. Эти значения представлены в табл. 2. Как следует из табл. 2, в образцах частиц нанопорошка ДНА около $46.5 \%$ атомов углерода от их общего количества находятся в состоянии $s p^{3}$-гибридизации, тогда как $\sim 26.8 \%$ атомов соответствуют состоянию углерода с $s p^{2}$-гибридизацией, а остальные атомы углерода находятся в составе гидроксильных (или эфирных) $\sim 24.5 \%$ и карбоксильных $\sim 2.2 \%$ групп (рис. $2, a$ ). В отличие от первичных частиц ДНА в образцах нанопорошка ПНА значительная часть атомов углерода $(67.8 \%$ от их общего количества) находится в состоянии $s p^{3}$-гибридизации, атомам углерода в состоянии $s p^{2}$-гибридизации соответствует $\sim 17.4 \%$, а остальные атомы углерода пребывают в составе гидроксильных (или эфирных) $\sim 13.0 \%$ и карбоксильных групп $\sim 1.7 \%$ (рис. $2, b$ ).

На рис. 2 приведены остовные линии кислорода $\mathrm{O} 1 s$ в образцах ДНА (рис. $2, a$ ) и ПНА (рис. $2, b$ ). Контуры линий кислорода О1s образцов ДНА и ПНА имеют почти одинаковые интенсивность и формы с шириной на полувысоте (FWHM) соответственно 2.5 и $2.57 \mathrm{eV}$. Видно, что в спектрах обоих образцов присутствуют различные кислородсодержащие функциональные группы. Согласно литературным данным (см. например, $[9,11,12])$, в интервале значений энергии связи $531.3-531.6 \mathrm{eV}$ лежат пики кислорода в составе карбонильных или карбоксильных групп, тогда как значения энергии связи выше $532.7 \mathrm{eV}$ характерны для линий кислорода в составе гидроксильных и сложноэфирных групп.

\section{Заключение}

Таким образом, результаты исследования методом РФЭС показывают, что первичные частицы нанопорошков ПНА состоят в основном из атомов углерода $(90.8 \%)$ и кислорода $(9.2 \%)$, остальные элементы $(\mathrm{N}, \mathrm{W}, \mathrm{Cl})$ проявляются на уровне следовых количеств. Частицы ДНА имеют практически идентичный с ПНА элементный состав: 90.6\% атомов углерода, 9.4\% атомов кислорода, другие элементы, включая атомы $\mathrm{N}$ и $\mathrm{S}$, не поддаются количественной оценке из-за слабой интенсивности сигнала, не превышающего уровень шума. Низкое содержание азота в образцах частиц ДНА может быть объяснено глубокой доочисткой исходного нанопорошка марки УДА-С-ГО, в результате которой с нано- частиц практически удалены сорбированные молекулы азота и азотсодержащие соединения.

В отличие от первичных частиц детонационного синтеза, где доля общая атомов углерода в состояниях $s p^{3}-, s p^{2}$-гибридизации и в составе функциональных групп $\mathrm{C}-\mathrm{O}-\mathrm{C} / \mathrm{C}-\mathrm{OH}, \mathrm{C}=\mathrm{O}$ и $\mathrm{HO}-\mathrm{C}=\mathrm{O}$ составляют соответственно $\sim 46.5, \sim 26.8$, и $\sim 26.7 \%$, в частицах нанопорошка, полученного измельчением природного алмаза, преобладают атомы углерода в состоянии $s p^{3}$ гибридизации $(\sim 67.8 \%)$. В них общая доля атомов углерода в состоянии $s p^{2}$-гибридизации не превышает $\sim 17.4 \%$ и в составе кислородсодержащих функциональных групп $\sim 14.7 \%$ соответственно.

\section{Конфликт интересов}

Авторы заявляют, что у них нет конфликта интересов.

\section{Список литературы}

[1] П.П. Шарин, А.В. Сивцева, В.И. Попов. Письма в ЖТФ, 46 (3), 46 (2020). DOI: 10.21883/PJTF.2020.03.48993.18045

[2] П.П. Шарин, А.В. Сивцева, С.П. Яковлева, М.М. Копырин, С.А. Кузьмин, В.И. Попов, Л.А. Никифоров. Известия вузов. Порошковая металлургия и функциональные материалы, 4, 55 (2019). DOI: dx.doi.org/10/17073/1997-308X-2019-4-55-67

[3] И.И. Кулакова. ФТТ, 46 (4), 621 (2004).

[4] V.I. Korepanov, H. Hamaguchi, E. Osawa, V. Ermolenkov, I.K. Lednev, B.J.M. Etzold, O. Levinson, B. Zousman, C.P. Epperla, H.-C. Chang. Carbon, 121, 322 (2017). DOI: http://dx.doi.org/10.1016/j.carbon.2017.06.012

[5] А.Л. Верещагин. Свойства детонационных наноалмазов (Изд-во Алтайского гос. тех. ун-та, Бийск, 2005)

[6] S. Stehlik, M. Varga, M. Ledinsky, V. Jrashek, A. Artemenko, H. Kozak, L. Ondic, V. Skakalova, G. Argentero, T. Pennycook, J. Meyer, A. Fejfar, A. Kromka, B. Rezek J. Phys. Chem., 119, 27708 (2015). DOI: $10.1021 /$ acs.jpcc.5b05259

[7] Д.Е. Николичев, А.В. Боряков, С.И. Суродин, Р.Н. Крюков. Анализ твердотельных гетеронаносистем методом РФЭС. Уиебно-методическое пособие (Изд-во Нижегородского гос. ун-та, Нижний Новгород, 2013)

[8] http://www.frpc.secna.ru/uda/propert.php Технология глубокой очистки УДА.

[9] А.Е. Алексенский, В.Ю. Осипов, А.Я. Вуль, Б.Я. Бер, А.Б. Смирнов. ФТТ, 43 (1), 140 (2001).

[10] Электронный ресурс. Режим доступа: http://xpspeak.software.informer.com/4.1

[11] C. Fang, Yu. Zhang, W. Shen, Sh. Sun, Zh. Zhang, L. Xue, X. Jia. Cryst. Eng. Comm., 19, 5727 (2017).

[12] M. Qi, J. Xiao, Y. Cheng, Zh. Wang, A. Jiang, Y. Guo, Z. Tao. AIP Advances, 7, 085012 (2017).

[13] А.В. Швидченко, А.Н. Жуков, А.Т. Дидейкин, М.В. Байдакова, М.С. Шестаков, В.В. Шнитов, А.Я. Вуль. Коллоид. журн., 78 (2), 218 (2016). DOI: $10.7868 / \mathrm{S} 0023291216020142$ 